\title{
Benefit of Using Sick Child Care Facilities to the Children and Their Parents
}

\author{
Kyoko Fukumoto', Mao Kawamura², Mayu Yoshitsugu3, Ikuko Sobue ${ }^{3 *}$ \\ ${ }^{1}$ Mazda Hospital, Hiroshima, Japan \\ ${ }^{2}$ Hiroshima University Hospital, Hiroshima, Japan \\ ${ }^{3}$ Division of Nursing Science, Graduate School of Biomedical \& Health Sciences, Hiroshima University, \\ Hiroshima, Japan \\ Email: kyoko.fkmt@gmail.com, mmaaoo.4517@gmail.com,m156156@hiroshima-u.ac.jp, \\ "sobue@hiroshima-u.ac.jp
}

Received 19 July 2016; accepted 22 August 2016; published 25 August 2016

Copyright (C) 2016 by authors and Scientific Research Publishing Inc.

This work is licensed under the Creative Commons Attribution International License (CC BY).

http://creativecommons.org/licenses/by/4.0/

(c) (i) Open Access

\section{Abstract}

Introduction: Sick child care is a form of nursing care provided temporarily for sick children when they cannot be cared for by their parents at home. To clarify the benefits of using sick child care facilities for children and their parents, we surveyed these parents about the benefits of such care and their needs. Method: Study design: Descriptive research. We studied parents whose children had used one of the 11 sick child care facilities for sick children in Hiroshima City in 2014. A total of 156 parents consented to participate in the study. We investigated their usage situation of sick child care, perceived benefits of such care, and care-related requests in a quantitative and qualitative manner. Results: Both nuclear families consisting of the dual income parents and their children and single-mother households reported that their children (mean age: 2.46 years [SD: 1.77 years]) had used sick child care because of infectious diseases. Approximately $10 \%$ of the parents were using the fee reduction systems of sick child care intended for people with a low income. Parents viewed sick child care as beneficial both in early the health recovery of children, and as support for child raising and working. On the other hand, some parents left their children at home alone when sick child care was not available due to the limited number of sick child care facilities and an insufficient capacity to accept children. Some parents desired an increased number of care facilities, as well as a reduction in or subsidies for care fees. Conclusion: The results of this study suggest that, to ensure children's health and safety, and support their parents for working and child raising, there is a need to increase the number of sick child care facilities along with expanding care services.

*Corresponding author. 


\section{Keywords}

\section{Benefits, Child Raising Support, Sick Child Care}

\section{Introduction}

The ways in which women balance working and child raising are both personal and national matters [1]. In Japan, to respond to the expansion of women's societal roles and changes in family demographics (an increase in the numbers of nuclear families consisting of the dual income parents and their children and single-parent households), the government is adopting various child raising measures, such as maternal leave and childcare systems [2]. These systems include services that visit all of the families having a new infant, and services that care for schoolchildren outside of school time.

In addition, as sick children may hinder their mothers' work, the above-mentioned measures include the provision of sick child care services that care for these children [3]. The service is a form of nursing care provided temporarily by nursery staff and nurses for children who mostly suffered infectional disease when they cannot be cared for by their parents, for reasons such as having to work. In 2012, approximately 490,000 sick children used a combined total of 1102 care facilities [4]. The primary objective of sick child care is to provide total care for sick children and child raising support for their parents [5]. In general, nursery staffs providing sick child care consider the important points of such care are to alleviate the pain of sick children, provide care targeting early recovery, give their parents care-related guidance, and advise these parents on child raising [6]-[9].

However, many studies have focused on the benefits of sick child care for working parents [10] [11]. Although, the benefits that children received from such care are important, few studies have investigated these benefits. To discuss how sick child care should be provided to ensure the health of aforementioned children, we surveyed their parents about the benefits of and issues regarding sick child care.

\section{Methods}

\section{Study Design: Descriptive Research}

The study participants consisted of one or both parents whose children had used one of the 11 nurseries for sick children in Hiroshima City that is an ordinance-designated city and prefectural seat of Hiroshima Prefecture between October and November 2014. In 2014, the city had a population of 1,190,629, and a child population of six years or younger of 78,466 [12]. Inclusion criteria for participants defined all adult users who use sick child care facility in Hiroshima City, because there are children brought up by not parents but adult such as grandparents. In Hiroshima City, care fees of sick child care are reduced for families receiving welfare support, those exempt from municipal tax, and those exempt from income taxes.

We investigated: 1) the parents' demographic variables (age, type of household, employment situation, and monthly disposable household income), 2) their usage of sick child care (age and diseases of their children, as well as the costs of and reasons for using such services), 3) annual number of days using care services, and 4) whether or not they had ever been unable to use sick child care, as well as actions taken in such circumstances. We used 18 items regarding the benefits of sick child care such as assistance for workers, child raising support, and benefits for children (Table A1), and 13 items regarding sick child care-related requests (Table A2). Each of these items had 4 possible responses. In addition, the one or both of the parents were asked to freely write down their opinions and desires regarding sick child care.

Written informed consent was obtained from the managers of 11 nurseries for sick children, because we asked the staff to distribute the questionnaires to parents using the nurseries. Staff members of these facilities then distributed the following documents to parents: an explanation form describing the study, a questionnaire, and selfaddressed envelopes (postage deferred payment mail). The parents were asked to reply only if they consented to participate in the survey. In addition, to calculate the response rate, we asked each investigated facility to count the number of questionnaires completed in the facility.

Missing quantitative values were handled according to each question item. Using SAS9.2, we performed exploratory factor analysis and the Wilcoxon signed-rank test. Parents using and not using the systems for reduc- 
ing care fees were classified based on their payment of these fees. For qualitative data analyses, the statements in the collected questionnaires were repeatedly reviewed, classified depending on their meaning, and encoded while maintaining the main points of these statements. The encoded data were labeled according to their similarities, based on which the data were divided into subcategories, categories, and core categories. To ensure data reliability, all analyses were performed by 4 researchers.

The study objective/methods and ethical considerations were explained to the above-mentioned managers in written and oral forms, as well as to the study parents using a written form. The study was conducted with the approval of the Ethics Committee, University of Hiroshima (http://home.hiroshima-u.ac.jp/gakujutu/rinri2/\#eki, Approval number; E-391).

\section{Results}

\subsection{Subjects}

We distributed a questionnaire to 408 parents whose children had used a nursery for sick children, and collected completed questionnaires from 156 of these parents (response rate: 38.24\%). The collected questionnaires were all analyzed. No significant differences of quantitative demographic variables were noted between 111 parents who answered the qualitative variables and 45 parents who did not answer the qualitative variables.

\subsection{Quantitative Data}

Of all parents, 147 were mothers; 98 and 32 were in their 30s and 40s, respectively (Table 1). Nuclear families consisting of the dual income parents and their children and single mothers numbered 131 and 14, respectively. The number of parents of full- and part-time positions was 101 and 43, respectively. The average working time was 8.29 hours $(\mathrm{SD}=1.52)$. In addition, 87 parents worked on weekends, and 7 were night-time workers. The monthly disposable household income was more than 400,000 yen for 70 parents, and less than 200,000 for 15 parents. The support system for reducing care fees conducted by municipality was used by 15 parents.

The average number of times using sick child care during the previous year was 4.37 (SD = 5.12). Most recently, the average number of days using sick child care was 1.98 (SD = 2.07), with the average number of hours using it per day being $8.38(\mathrm{SD}=1.58)$. In addition, each of 8 parents placed 2 children in such care at any one given time. The mean age of the children using care services was 2.46 years $(\mathrm{SD}=1.77)$, and most of them had infectious diseases (Table 2). In addition, from multiple answers, parents used sick child care for the reason that they had no relatives to take care of their children $(n=94)$, they were reluctant to take time off from work despite being able to take paid leave $(n=84)$, or they were unable to bring their children to their workplace $(n=$ 82). A total of 111 parents who used sick child care arrived at their workplace late, or had to leave early when using sick child care.

During the previous year, of all parents who used sick child care, 44 parents had been unable to use such care at least once, with the average number of times it was unavailable being $1.07(\mathrm{SD}=0.93)$. The major reason for unavailable sick child care was because the maximum capacity of children had been reached $(\mathrm{n}=34)$. No parents reported financial issues as a reason for being unable to use such care. When sick child care was unavailable, the action of parents included: 1) taking the day off from work (121 mothers and 36 fathers), 2) placing children in the care of their grandparents (42 parents), and 3) making children stay at home alone (3 parents).

Of 156 parents who used sick child care, 154 parents desired to continue using sick child care. A polychoric correlation matrix was created for the 18 items (each of which had 4 possible options) regarding the benefits of sick child care. The data obtained from these items were then subjected to exploratory factor analysis (unweighted least squares, promax rotation) (Table 3), which led to the extraction of the following 2 factors: 1) benefits for parents (the parents' relief of child raising and ability to work due to sick child care usage) and 2) benefits for children (the early health recovery, infection prevention and developmental care for sick child). Both the scale used and these 2 factors showed a polychoric ordinal alpha coefficient of $\geq 0.74$. The score of sick child care's benefits for parents was significantly higher than that for their children $(\mathrm{P}<0.01)$.

A polychoric correlation matrix was created for the 13 items regarding sick child care-related requests. The data obtained from these items were then subjected to exploratory factor analysis (unweighted least squares, promax rotation) (Table 4), which led to the extraction of the following 3 factors: 1) subsidies for care fees, 2) the expansion of care services, and 3) an increase in the capacity to accept children. Both the scale used and 
Table 1. Demographic variables $\mathrm{N}=156$.

\begin{tabular}{|c|c|c|c|}
\hline Indices & Items & $\mathrm{n}$ & $\%$ \\
\hline \multirow{3}{*}{$\begin{array}{l}\text { Respondents' relationship } \\
\text { with their children }\end{array}$} & Mother & 147 & 94.84 \\
\hline & Father & 7 & 4.52 \\
\hline & Grandmother & 1 & 0.65 \\
\hline \multirow{4}{*}{ Age range } & $20 \mathrm{~s}$ & 23 & 14.84 \\
\hline & $30 \mathrm{~s}$ & 98 & 63.23 \\
\hline & $40 \mathrm{~s}$ & 32 & 20.65 \\
\hline & $50 \mathrm{~s}$ & 2 & 1.29 \\
\hline \multirow{6}{*}{ Type of household } & Parents and their children (dual income) & 131 & 84.52 \\
\hline & Parents and their children (with only the father working) & 2 & 1.29 \\
\hline & Grandparents, parents, and their children (dual income) & 6 & 3.87 \\
\hline & Mother and children & 10 & 6.45 \\
\hline & Grandparents, mother, and children & 4 & 2.58 \\
\hline & Others & 2 & 1.29 \\
\hline \multirow{10}{*}{ Employment status } & Full-time worker & 101 & 65.16 \\
\hline & Part-time worker & 43 & 27.74 \\
\hline & Dispatched employee & 4 & 2.58 \\
\hline & Self-employed business & 2 & 1.29 \\
\hline & Executive officer & 1 & 0.65 \\
\hline & Unemployed & 1 & 0.65 \\
\hline & Others & 3 & 1.94 \\
\hline & Work hours/day (Mean, SD) & 8.29 & 1.52 \\
\hline & Working on weekends & 87 & 56.49 \\
\hline & Working at night & 7 & 4.67 \\
\hline \multirow{7}{*}{ Monthly disposable income (yen) } & $\geq 100,000$ to $<150,000$ & 3 & 2.01 \\
\hline & $\geq 150,000$ to $<200,000$ & 12 & 8.05 \\
\hline & $\geq 200,000$ to $<250,000$ & 8 & 5.37 \\
\hline & $\geq 250,000$ to $<300,000$ & 11 & 7.38 \\
\hline & $\geq 300,000$ to $<350,000$ & 22 & 14.77 \\
\hline & $\geq 350,000$ to $<400,000$ & 23 & 15.44 \\
\hline & $\geq 400,000$ & 70 & 46.98 \\
\hline \multirow{4}{*}{$\begin{array}{l}\text { Fees paid by those using the systems } \\
\text { for reducing care fees (yen) }\end{array}$} & 0 & 6 & 3.9 \\
\hline & 500 & 1 & 0.65 \\
\hline & 1000 & 2 & 1.3 \\
\hline & 1500 & 6 & 3.9 \\
\hline \multirow{3}{*}{$\begin{array}{l}\text { Fees paid by those not using the systems } \\
\text { for reducing care fees (yen) }\end{array}$} & 2000 & 113 & 73.38 \\
\hline & 2500 & 25 & 16.23 \\
\hline & 2800 & 1 & 0.65 \\
\hline
\end{tabular}

Due to missing values, the total number does not represent the total percentage for some items. 
Table 2. Usage of sick child care $\mathrm{N}=156$.

\begin{tabular}{|c|c|c|c|}
\hline Indices & Items & $\mathrm{n}$ & $\%$ \\
\hline \multirow{11}{*}{$\begin{array}{c}\text { Diseases } \\
\mathrm{n}=154\end{array}$} & Cold & 88 & 57.14 \\
\hline & Bronchitis or pneumonia & 13 & 8.44 \\
\hline & Chickenpox & 8 & 5.19 \\
\hline & Middle-ear infection & 8 & 5.19 \\
\hline & Conjunctivitis & 7 & 4.55 \\
\hline & Mumps & 6 & 3.90 \\
\hline & Vomiting or diarrhea & 6 & 3.90 \\
\hline & Hemolytic streptococcal infection & 3 & 1.95 \\
\hline & Hand-foot-and-mouth disease & 3 & 1.95 \\
\hline & Asthma & 3 & 1.95 \\
\hline & Others & 9 & 5.84 \\
\hline \multirow{13}{*}{$\begin{array}{l}\text { Reasons for using } \\
\text { sick child care } \\
\mathrm{n}=156\end{array}$} & I have no nearby relatives to look after my child & 94 & 60.26 \\
\hline & I could have taken paid leave, but I was reluctant to do so & 84 & 53.85 \\
\hline & I cannot bring my child to my workplace & 82 & 52.56 \\
\hline & No one at my workplace was able to do my work for me & 55 & 35.26 \\
\hline & I had work that had to be done on that day & 54 & 34.62 \\
\hline & I was unable to take time off from work & 53 & 33.97 \\
\hline & $\begin{array}{l}\text { I thought that it was better to leave my child in a facility } \\
\text { specializing in caring for sick children }\end{array}$ & 29 & 18.59 \\
\hline & $\begin{array}{l}\text { My relatives were unable to look after my child, } \\
\text { for reasons such as a disease or work }\end{array}$ & 25 & 16.03 \\
\hline & $\begin{array}{l}\text { I work on a part-time basis, and so my salary will } \\
\text { be reduced if I take time off work }\end{array}$ & 22 & 14.1 \\
\hline & I am concerned that I may be dismissed from work if I take time off & 14 & 8.97 \\
\hline & I had no choice but to use sick child care for a reason other than work & 4 & 2.56 \\
\hline & I was sick & 2 & 1.28 \\
\hline & Others & 7 & 4.49 \\
\hline \multirow{9}{*}{$\begin{array}{l}\text { Actions taken when sick } \\
\text { child care was unavailable } \\
\qquad n=134\end{array}$} & The child's mother took the day off from work & 121 & 90.3 \\
\hline & The child's father took the day off from work & 36 & 26.87 \\
\hline & The child was left in the care of their grandparents & 42 & 31.34 \\
\hline & The child's grandparents took the day off from work & 11 & 8.21 \\
\hline & The child was left in the care of a relative or acquaintance & 11 & 8.21 \\
\hline & A babysitter (e.g., a child raising helper or volunteer) was hired & 7 & 5.22 \\
\hline & The child was left at home alone & 3 & 2.24 \\
\hline & The child was taken care of by their non-working parent & 1 & 0.75 \\
\hline & Others & 5 & 3.73 \\
\hline
\end{tabular}

Due to missing values, the total number does not represent the total percentage for some items. 
Table 3. Benefits of sick child care $\mathrm{N}=156$.

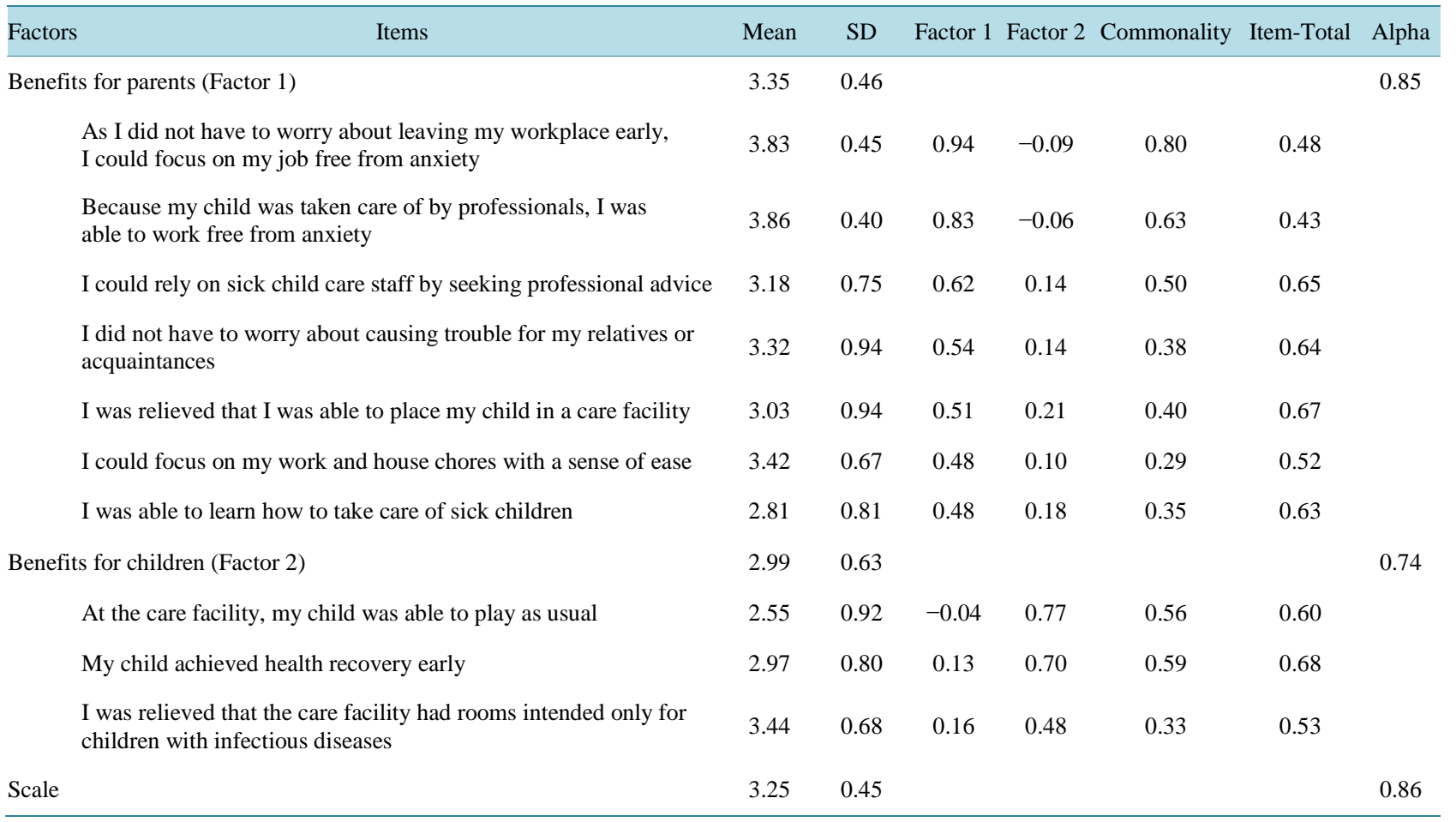

Exploratory factor analysis was conducted using unweighted least squares with promax rotation. Factor 1 "benefits for parents," because the factor reflected the parents' relief of child raising and ability to work due to sick child care usage. Factor 2 "benefits for children," because the factor reflected the early health recovery, infection prevention and developmental care for sick child. Factor 1 vs. Factor 2; Wilcoxon signed-rank test; the probability values showed P < 0.01. Item-Total Correlation; Spearmans correlations; all of the probability values showed $\mathrm{P}<0.01$; Alpha represents Polycoric ordinal alpha coefficient.

\section{Table 4. Parents' requests regarding sick child care $\mathrm{N}=156$.}

\begin{tabular}{|c|c|c|c|c|c|c|c|c|}
\hline Factors & Mean & $\mathrm{SD}$ & Factor 1 & Factor 2 & Factor 3 & Commonality & Item-Total & Alpha \\
\hline Subsidies for care fees (Factor 1) & 2.82 & 0.74 & & & & & & 0.96 \\
\hline I desire lower care fees & 2.77 & 0.93 & 0.79 & -0.11 & 0.08 & 0.59 & 0.63 & \\
\hline I desire financial support from my workplace & 2.70 & 1.03 & 0.77 & 0.00 & 0.00 & 0.59 & 0.66 & \\
\hline I wish that care fees were fully subsidized & 2.51 & 0.97 & 0.72 & 0.17 & -0.12 & 0.61 & 0.70 & \\
\hline $\begin{array}{l}\text { I desire a reduction in fees for nursery school and } \\
\text { sick child care when using such care }\end{array}$ & 3.14 & 0.98 & 0.70 & 0.14 & -0.14 & 0.56 & 0.65 & \\
\hline Expansion of care services (Factor 2) & 2.63 & 0.71 & & & & & & 0.82 \\
\hline I desire an increase in the number of nursery staff members & 2.59 & 0.83 & 0.00 & 0.93 & 0.07 & 0.90 & 0.66 & \\
\hline I wish that nurseries were open on weekends and holidays & 2.79 & 0.96 & -0.13 & 0.51 & 0.15 & 0.29 & 0.40 & \\
\hline Increase in the capacity to accept children (Factor 3) & 3.46 & 0.61 & & & & & & 0.83 \\
\hline I desire an increased capacity to accept children & 3.27 & 0.81 & -0.05 & 0.14 & 0.82 & 0.77 & 0.45 & \\
\hline I desire an increase in the number of care facilities & 3.66 & 0.59 & 0.07 & 0.05 & 0.78 & 0.67 & 0.44 & \\
\hline Scale & 2.89 & 0.54 & & & & & & 0.86 \\
\hline
\end{tabular}

Exploratory factor analysis was conducted using unweighted least squares with promax rotation. The mean factor score of factor 3 was significantly higher than that of two other factors $(\mathrm{P}<0.01$ ), Wilcoxon signed-rank test or paired t-test, Bonferroni correction $\mathrm{P}<0.017$. Item-Total Correlation; Spearmans correlations; all of the probability values showed $\mathrm{P}<0.01$; Alpha represents Polycoric ordinal alpha coefficient. 
these 3 factors showed a polychoric ordinal alpha coefficient of $\geq 0.82$. The score for Factor 3 was significantly higher than those for Factors 1 and 2.

\subsection{Qualitative Data}

The free descriptions of their opinions and desires regarding sick child care were divided into the following 3 core categories: the 1) benefits of sick child care, 2) difficulties in utilizing sick child care, and 3) requests regarding sick child care (Table 5). These core categories comprised 6 categories consisting of 21 subcategories and 51 labels. In this article, the categories, subcategories, and parents' descriptions are shown below as [ ], « », and " " combined with italics, respectively.

\section{Table 5. Benefits of sick child care $\mathrm{N}=111$.}

\begin{tabular}{|c|c|c|c|}
\hline Core categories & Categories & Subcategories & Labels \\
\hline \multirow[t]{18}{*}{ Benefits of sick child care } & Parents’ relief & & Secure income \\
\hline & & $\begin{array}{l}\text { Sense of relief because } \\
\text { of being able to work }\end{array}$ & $\begin{array}{l}\text { Sense of relief because of being able } \\
\text { to work through using sick child care }\end{array}$ \\
\hline & & & $\begin{array}{l}\text { Parents do not have to worry about being } \\
\text { called by the nursery during work }\end{array}$ \\
\hline & & & Being able to manage work and child raising \\
\hline & & & Parents do not have to take time off work \\
\hline & & & $\begin{array}{l}\text { Relief from anxiety due to the possibility } \\
\text { of dismissal from work }\end{array}$ \\
\hline & & $\begin{array}{l}\text { Sense of relief due to } \\
\text { the expertise of sick }\end{array}$ & Treatment provided by pediatricians \\
\hline & & child care & High-quality nursing care and childcare \\
\hline & & & Actions taken by sick child care staff \\
\hline & & Gratitude for support & Absence of people to rely on \\
\hline & & & Relatives living far from home \\
\hline & & & Both parents working \\
\hline & Children's positive & Children's positive & Children enjoy staying at care facilities \\
\hline & reactions & child care & Children feel comfortable staying at care facilities \\
\hline & & & Children have an enjoyable time at care facilities \\
\hline & & & Children are willing to go to care facilities \\
\hline & & $\begin{array}{l}\text { Sense of mental peace } \\
\text { achieved through }\end{array}$ & Parents feel a sense of relief \\
\hline & & $\begin{array}{l}\text { children’s positive } \\
\text { reactions }\end{array}$ & Parents’ relief from guilt \\
\hline \multirow{6}{*}{$\begin{array}{l}\text { Difficulties in utilizing } \\
\text { sick child care }\end{array}$} & Difficulties perceived & $\begin{array}{l}\text { Arriving at workplace } \\
\text { late and leaving early }\end{array}$ & Late starting time of care services \\
\hline & & & Early ending time of care services \\
\hline & & $\begin{array}{l}\text { Systems for utilizing } \\
\text { sick child care }\end{array}$ & $\begin{array}{l}\text { The systems for making a reservation } \\
\text { are not efficient }\end{array}$ \\
\hline & & & $\begin{array}{l}\text { Whether or not a reservation has been } \\
\text { made is clarified late }\end{array}$ \\
\hline & & & $\begin{array}{l}\text { It is necessary to receive a medical consultation at a } \\
\text { medical center in the same location as the care facility }\end{array}$ \\
\hline & & & It takes time to receive a medical consultation \\
\hline
\end{tabular}




\section{Continued}

\begin{tabular}{|c|c|c|c|}
\hline & & Care fees & $\begin{array}{l}\text { Burden of paying fees for both nursery school } \\
\text { and sick child care }\end{array}$ \\
\hline & & & Fees for sick child care need to be paid in advance \\
\hline & & & Care service users have to pay the entire fee \\
\hline & & & Income is only barely sufficient for care fees \\
\hline & & $\begin{array}{l}\text { Anxiety about job } \\
\text { insecurity }\end{array}$ & Being unable to take time off work \\
\hline & & & Continued work is difficult without sick child care \\
\hline & & & $\begin{array}{l}\text { Need to consider what other employees at workplace } \\
\text { think about the usage of sick child care }\end{array}$ \\
\hline & & $\begin{array}{l}\text { Difficulties perceived } \\
\text { by children }\end{array}$ & $\begin{array}{l}\text { Feeling uncomfortable being surrounded by } \\
\text { people in the care facility }\end{array}$ \\
\hline & & & Children are reluctant to go to care facilities \\
\hline & Potential difficulties & Numbers of care facilities & $\begin{array}{l}\text { Unavailable sick child care due to the limited } \\
\text { number of care facilities }\end{array}$ \\
\hline & & such facilities & $\begin{array}{l}\text { Unavailable sick child care due to an insufficient } \\
\text { capacity to accept children }\end{array}$ \\
\hline & & $\begin{array}{l}\text { Age limit for utilizing } \\
\text { sick child care }\end{array}$ & Age limit for utilizing sick child care \\
\hline & & Infection & $\begin{array}{l}\text { Anxiety due to the possibility that an individual's } \\
\text { child may be infected by other children }\end{array}$ \\
\hline & & & $\begin{array}{l}\text { Anxiety due to the possibility that an individual's child } \\
\text { may spread their infectious disease to other children }\end{array}$ \\
\hline Requests regarding sick & $\begin{array}{l}\text { Requests that parents } \\
\text { wanted to make to care }\end{array}$ & Business hours & Desire for the earlier starting time of care services \\
\hline & facilities & & Desire for the later ending time of care services \\
\hline & & $\begin{array}{l}\text { Number of days sick child } \\
\text { care is available }\end{array}$ & $\begin{array}{l}\text { Desire for the provision of care } \\
\text { services on weekends }\end{array}$ \\
\hline & & $\begin{array}{l}\text { Capacity to accept } \\
\text { children }\end{array}$ & $\begin{array}{c}\text { Desire for an increase in the number of care } \\
\text { staff members }\end{array}$ \\
\hline & & $\begin{array}{l}\text { Information provided for } \\
\text { care service users }\end{array}$ & $\begin{array}{l}\text { Desire for the introduction of care } \\
\text { staff to service users }\end{array}$ \\
\hline & & Reservation systems & Desire for efficient reservation systems \\
\hline & & Number of care facilities & $\begin{array}{l}\text { Desire for an increase in the } \\
\text { number of care facilities }\end{array}$ \\
\hline & $\begin{array}{l}\text { Requests regarding factors } \\
\text { other than care facilities }\end{array}$ & & $\begin{array}{l}\text { Desire for sick child care facilities to be set up } \\
\text { in the same location as nursery schools }\end{array}$ \\
\hline & & & $\begin{array}{l}\text { Desire for every medical center to accept } \\
\text { and look after sick children }\end{array}$ \\
\hline & & Care fees & Desire for subsidies for care fees \\
\hline & & & $\begin{array}{l}\text { Desire for the reduction of care fees according } \\
\text { to the numbers of accepted children and days } \\
\text { using care services }\end{array}$ \\
\hline & & $\begin{array}{l}\text { Information provided } \\
\text { for those not using }\end{array}$ & $\begin{array}{l}\text { Dissemination of sick child care facilities } \\
\text { with a sufficient capacity }\end{array}$ \\
\hline & & & Content of care services \\
\hline
\end{tabular}




\subsubsection{Benefits of Sick Child Care}

The benefits of sick child care were [parents' relief] and [children's positive reactions]. By utilizing sick child care, parents showed a sense of relief due to being able to work and the expertise of such care, and were grateful to care staff as child raising supporters. In addition, they felt a sense of mental peace resulting from children's positive reactions to sick child care.

«Sense of relief because of being able to work»

"If I take time off from work, my salary will be reduced. As a single mother, I greatly benefit from sick child care."

«Sense of relief due to the expertise of sick child care»

"My sense of relief was markedly greater when using sick child care than when leaving my child at home alone. I was glad that care staff appropriately dealt with my child's symptoms."

«Sense of mental peace achieved through children's positive reactions»

"My child feels comfortable staying at the nursery, and always smiles at me when I pick them up. Therefore, I do not feel bad asking care staff to look after my child."

\subsubsection{Difficulties in Utilizing Sick Child Care}

Parents felt difficulty utilizing sick child care, for reasons such as the financial burden (fees for both nursery school and sick child care), and/or the possibility of arriving at the workplace late or having to leave early. In addition, they were concerned about the possibility of being unable to use sick child care due to the limited number of care facilities and children accepted by these facilities, as well as to the age limit for utilizing such care.

[Difficulties perceived though experience]

«Arriving at workplace late and leaving early»

"When using sick child care, it is very difficult to arrive at my workplace before 8:00, and work until 18:00."

«Care fees»

"It is a little difficult to pay fees for both nursery school and sick child care."

"Because I am a part-time worker, my salary is only barely sufficient for sick child care fees."

«Difficulties perceived by children»

"Because my child uses sick child care only when they are sick, they feel uncomfortable being surrounded by people in the care facility."

[Potential difficulties]

"Age limit for utilizing sick child care»

"Because sick child care is only available to children aged 10 years or younger, I have no idea what to do after my child becomes 11 years old."

\subsubsection{Requests Regarding Sick Child Care}

The requests of the parents wanted to make to nurseries for sick children included longer business hours, an increased number of days sick child care is available, increased number of accepted children, and efficient reservation systems. In addition, the requests parents wanted to make to administrative bodies included increased subsidies for service fees, the reduction of these fees according to the numbers of service users and days for utilizing care services, and a higher number of care facilities.

[Requests that parents wanted to make to care facilities]

«Business hours»

"If the business hours were longer at the care facility, I would not have to worry about arriving at my workplace late or leaving early."

«Capacity to accept children»

"Because the capacity to accept children is not sufficient, I wish for it to be increased according to the time of year.”

[Requests regarding factors other than care facilities]

«Care fees»

"I wish for subsidies for care fees to be provided when 2 or more of my children use nurseries at any one time.” 


\section{Discussion}

Sick child care users were mainly from nuclear families consisting of the dual income parents and their children or single-mother households. As was the case in previous studies [13] [14], in the present study, parents placed their children, mainly those aged $<3$ years with infectious diseases, in sick child care facilities for the reason that these parents had no relatives to take care of their children, had difficulty taking time off work, or were unable to bring their children to their workplace.

In this study, approximately $10 \%$ of the parents were using the care fee reduction system of sick child care. In addition, no parents reported financial issues as the reason for being unable to use such care. In Japan, where approximately $40 \%$ of the workers are non-regular employees, sick children are a major risk factor not only for a reduced income, but also for dismissal from work [14]. For those at high risk of suffering from a reduced income due to taking time off work, such as single mothers, the systems for reducing care fees help to ensure a stable income and job security.

Parents viewed sick child care as helpful not only for employment, but also for child raising. They considered professional care to be of higher quality than care provided by themselves, and recognized the early recovery of children and isolation of those with infectious diseases as beneficial. Parents relied on sick child care staff by seeking professional advice. In addition, by acknowledging that their children are able to spend an enjoyable time at care facilities, these parents reduced their sense of guilt, and achieved a sense of mental peace. These positive views are consistent with those reported in previous studies investigating care provided by nursery staff, care provided to achieve the early recovery and mental peace of sick children, or care- and child raising-related guidance given to parents [6]-[9]. The results of our study suggest that children's positive reactions to sick child care, and parents' sense of trust and relief due to high-quality care become the basis for their job security.

Furthermore, one of the merits of sick child care services is the appropriate management of stressful situations for children as service users by facility staff. Such situations are represented by separation anxiety observed in children when being separated from their mothers. Separation from the mother and unfamiliar environments cause marked anxiety, fear, and stress in children. The time needed to stabilize after being separated from their mothers in the morning in facilities, leading to crying or other manifestations of separation anxiety, is longer in infants aged 8 months to 2 years [15]. The proportion of those in a bad mood is higher among 1-year-olds compared with older children [16]. It has also been noted that separation anxiety is more marked among children with severer conditions, regardless of the age. Isolation due to infectious diseases increases such distress [17]. To guide children toward the development of appropriate attachment to facility staff, the following care approaches may be necessary, particularly for sick children with marked separation anxiety: 1) accepting their needs; and 2) comforting them if they are crying or fussy [18]. Facility staff provides care based on development stages; for example, they hold younger children in their arms for a longer period, while treating older children with joyful play activities and fellows [16].

Sick children are subject to stress related to preparation for sick child care service use, such as waking up and taking breakfast earlier than usual [19]. In addition, nearly half of such children do not ingest sufficient nutrients at breakfast, or appropriately take their morning medications due to their poor physical conditions or a lack of time for their mothers to care for them. If the facility is located at some distance, both the durations of travelling and care are prolonged, consequently increasing the child's and parents' mental and physical burdens. Not being faced by sick children receiving care in their homes, such burdens are specific to sick child care service users. Therefore, facility staff makes efforts to minimize children's burden of using these services, and enhance benefits for them and their mothers by supplementing child care, if insufficient due to their parents' poor parenting abilities and living conditions, and providing approaches in accordance with individual children's developmental stages and pathological conditions.

On the other hand, a major issue identified was that sick child care was sometimes unavailable due to the limited number of care facilities and an insufficient capacity to accept children. During the previous year, approximately $30 \%$ of the parents had been unable to use such care at least once due to overcrowded care facilities. In addition, as was the case in previous studies [10] [14], some parents left their children at home alone when sick child care was unavailable. In the US and UK, it is prohibited to leave children with a health risk at home alone [20] [21]. In Sweden, each set of parents gets 480 days of paid parental leave per child, which must be claimed before the child turns eight [22]. In Japan, the annual number of days children aged 0 - 6 years are absent from nursery school ranges from 10 to 22 days [10]; however, parents with one preschool child are allowed 
to take child care leave only for up to 5 days each year [23]. Therefore, some parents leave their sick children at home alone, or make them attend nursery school [14] [24] [25]. Thus, parents who do not have anyone to look after their children strongly desire a higher upper age limit for utilizing sick child care, as well as an increase in the capacity to accept children and the number of care facilities.

Parents encountered difficulties in using sick child care, because they would have to arrive at their workplace late or leave early. The business hours of sick child care facilities (10 hours) [26] are shorter than those of nursery schools (11.6 hours) [27]. In addition, when utilizing sick child care, parents usually need to accompany their children to a medical consultation in the morning. Furthermore, some parents utilize sick child care facilities located far from home when a nearby facility is unavailable, for reasons such as the shortage of such facilities and an insufficient capacity to accept children. Due to these factors, it is difficult for parents to work regular hours. Moreover, it is a heavy burden for sick children to go to a care facility far from home, and stay there for a long time; hence, from the perspective of caring for children, there is a need to increase the number of sick child care facilities.

Concerning the cost of sick child care (standard fee of 2000 yen per day), parents reported an increased financial burden due to: the repeated usage of such care, service utilization by more than one childat any one given time, and fees for nursery school in addition to those for sick child care. In Japan, the mean annual income of households with children is 6.07 million yen (monthly disposable salary: 330,000 - 375,000 yen) [28]. The standard monthly childcare fee for the first child aged $<3$ years is 44,500 yen, and that for the first and second child aged $<3$ years is 66,750 yen [2]. When a child develops influenza, and will be absent from nursery school for at least 5 days, a fee of 10,000 yen for sick child care is necessary [29]. Thus, it may be very difficult for households, in which both parents must work for financial reasons, to pay sick child care fees (repeated usage of such care, and service utilization by more than one child at any one time), in addition to nursery school fees.

In the present study, because we investigated only one municipality employing a system for reducing care fees, we were not able to clarify differences according to the type of household or presence/absence of such systems. To design policies based on the needs of care service users, it is necessary to investigate the characteristics of care facility users (e.g., type of household), and assess the existing care-related measures. In addition, to improve the quality of sick child care, there is a need to investigate sick children's and their parents' characteristics perceived by nursery staff and nurses, and clarify the details of care services.

\section{Conclusion}

Sick child care was used mainly by children with infectious diseases who were from single-mother or nuclear families consisting of the dual income parents and their children. Also, parents used sick child care for the reason that they had no relatives to take care of their sick children, or they could not take time off from work. Parents viewed such care as beneficial in the health recovery of children, as well as in supporting their parents for child raising and work. Because of the difficulties in utilizing sick child care, such as the financial burden and/or the possibility of arriving at the workplace late or having to leave early, parents desired improved care services, such as an increased number of care facilities, longer business hours, and an increased number of days sick child care was available.

\section{Funding}

This study was funded by a Grant-in-Aid for scientific research expenses of the Japan society for the Promotion of Science (25463472).

\section{Conflict of Interests}

The authors have no conflicting interest in this study.

\section{References}

[1] Killey, M. (2000) Lone Mothers between Paid Work and Care: The Policy Regime in Twenty Countries. Ashgate, Hampshire.

[2] Child Raising Center, Cabinet Office, Government of Japan (2015) New Child Raising Support System. http://www8.cao.go.jp/shoushi/shinseido/outline/pdf/setsumei.pdf 
[3] Director-General of the Equal Employment, Children and Families Bureau, Ministry of Health, Labour and Welfare (2015) Provision of Sick Child Care.

http://www8.cao.go.jp/shoushi/shinseido/law/kodomo3houan/pdf/h270717/t12.pdf

[4] Cabinet Office (2013) Sick Child Care.

http://www8.cao.go.jp/shoushi/shinseido/meeting/kodomo kosodate/b 8/pdf/s2-2.pdf

[5] Japan Sick Childcare Association (2016) Concept of Sick Child Care. http://www.byoujihoiku.net/about/

[6] Kanda, T. and Miyazu, S. (2010) Research on Childcare Nursing at the Child Care Room for Sick Children: Based on the Viewpoint of Child Care Support. Bulletin of the Faculty of Education Hirosaki University, 103, 105-109. http://repository.ul.hirosaki-u.ac.jp/dspace/bitstream/10129/3401/1/BFEduHirosaki_103_105.pdf

[7] Tanaka, Y. (2011) The Perception of Services in Nurses as to the Day Care for Sick Children. The Journal of Child Health, 70, 365-370.

http://mol.medicalonline.jp/library/journal/download?GoodsID=cx3child/2011/007003/006\&name=0365-0370j\&UserI $\underline{\mathrm{D}=133.41 .94 .76 \& b a s e=\text { jamas_pdf }}$

[8] Fujiwara, Y. (2007) The Role of an Institution for Day Care for Sick Children: Focusing on Evaluation of the Staff. Japan Society of Research on Early Childhood Care and Education, 45, 183-190.

http://ci.nii.ac.jp/els/110006532285.pdf?id=ART0008518110\&type=pdf\&lang=en\&host=cinii\&order no=\&ppv type= 0\&lang_sw $=\& n o=1453991111 \& \mathrm{cp}=$

[9] Kanaizumi, S., Nakashita, T., Yajima, M. and Ohno, A. (2003) Characteristics of Nursing and Nursing Intervention Skills Required in a Nursery Room for Children Recovering from Common Illnesses. Bulletin of Gumma Paz Gakuen College, 5, 87-97.

http://ci.nii.ac.jp/els/110004708541.pdf?id=ART0007450730\&type=pdf\&lang=en\&host=cinii\&order_no=\&ppv_type= 0\&lang_sw=\&no=1453991466\&cp=

[10] Fukada, M., Minamimae, K. and Kasagi, T. (2001) Analysis of a Method of Sick Child Care and Nursing Role. The Journal of the Yonago Medical Association, 52, 183-195.

http://mol.medicalonline.jp/library/journal/download?GoodsID=eb3yonai/2001/005203/004\&name=0183-0195j\&User ID=133.41.94.76\&base=jamas_pdf

[11] Tanihara, M., Abe, H., Mori, T. and Okada, K. (2010) Parents’ Response to Their Sick Child and the Current Status of Sick-Child-Care Support Needs. Kawasaki Medical Welfare Journal, 19, 411-418.

http://www.kawasaki-m.ac.jp/soc/mw/journal/jp/2010-j19-2/42 tanihara.pdf

[12] Hiroshima City (2016) Hiroshima City Statistics Book (2015 Version). http://www.city.hiroshima.lg.jp/www/contents/1457585078403/index.html

[13] Yamada, Y. and Harada, K. (2009) Roles of Sick Child Care Based on a Questionnaire Survey Involving Care Users. The Child Health Ishikawa, 21, 7-11.

[14] Kamimura, A., Kawamoto, M., Nagamatsu, S., Takahata, T., Yokoyama, M. and Nakasato, Y. (2007) Two-Year Experience of Operating a Sick Child Care Facility-Based on Past Records and the Results of a Questionnaire Survey Involving Care Users. The Journal of the Saitama Medical Society, 41, 309-312.

[15] Sato, M., Sato, T., Ueda, A. and Nishikawa, R. (2015) Status of Sick Child Care Service Use by New Children and Their Pathological Conditions-A Quantitative Analysis of Nursing and Child Care Services for Sick Children: The 4th Report. Journal of Daycare Research for Sick Children, 6, 35-41.

[16] Inukai, K. (2010) Discussing Separation Anxiety in Sick Child Care Facilities. The Journal of Care and Education in Pediatrics, 8, 76-82.

[17] Fukushi, T., Nanato, A., Harako, M., Saito, M., Nagamine, K. and Arai, K. (2013) Infectious Disease Precaution and Care Plan in Day Care Room for Sick Child. The Journal of Care and Education in Pediatrics, 11, 42-55.

[18] A Handbook for Childcare Workers, Nurses, and Other Professionals Involved with Care Services for Sick and Convalescent Children: Health Labour Sciences Research Grants FY 2014 (For Basic Research Projects for Next-Generation Growth to Overcome Developmental Diseases); <Status of Care Services for Sick and Convalescent Children and Measures to Improve Their Quality> (2015) A Handbook for Childcare Workers, Nurses, and Other Professionals Involved with Care Services for Sick and Convalescent Children. www.nhhk.net/health/byoujibyougojihandbook2.pdf

[19] Uehara, H., Takaya, M., Saito, A., Kizaki, A., Arata, Y., Nishida, T., et al. (2015) A Status Survey on the Morning Routines of Sick Children and Their Parents. Journal of Daycare Research for Sick Children, 6, 42-46.

[20] Child Welfare Information Gateway (2013) Leaving Your Child Home Alone. https://www.childwelfare.gov/pubpdfs/homealone.pdf

[21] National Society for the Prevention of Cruelty to Children (2016) Staying Home Alone. https://www.nspcc.org.uk/preventing-abuse/keeping-children-safe/leaving-child-home-alone/

[22] Swedish Institute (2016) Children in Sweden. https://sweden.se/society/children-and-young-people-in-sweden/ 
[23] Ministry of Health, Labour and Welfare (2010) Outline of the Child Care and Family Care Leave Law. http://www.mhlw.go.jp/general/seido/koyou/ryouritu/aramashi.html

[24] Sato, M. (2006) Research into the Needs of Day Nursery Users for Children with Sickness. Journal of Japanese Red Cross Toyota College of Nursing, 2, 29-34. http://ci.nii.ac.jp/naid/110006455356/en

[25] Ohki, N. (2003) The Actual Conditions Involved in Taking Care of Nursery School Children during Illness and the Parental Needs for Social Supports. The Journal of Child Health, 62, 350-358.

http://mol.medicalonline.jp/library/journal/download?GoodsID=cx3child/2003/006203/008\&name=0350-0358j\&UserI $\mathrm{D}=133.41 .94 .76$ \&base=jamas $\mathrm{pdf}$

[26] Japan Sick Childcare Association (2009) Current State of and Issues Regarding Sick Child Care. http://www.mhlw.go.jp/shingi/2009/09/dl/s0930-9d.pdf

[27] Japan National Council of Social Welfare, National Child Care Council (2012) Nationwide Report on the Characteristics of Childcare Centers for 2011. http://www.zenhokyo.gr.jp/cyousa/201209.pdf

[28] Ministry of Health, Labour and Welfare (2011) Overview of Comprehensive Survey Regarding Living Conditions for 2010. http://www.mhlw.go.jp/toukei/saikin/hw/k-tyosa/k-tyosa10/

[29] Ministry of Education (2013) Infectious Diseases That Should Be Prevented at Schools. http://www.mext.go.jp/a_menu/kenko/hoken/_icsFiles/afieldfile/2013/05/15/1334054_01.pdf 


\section{Appendix}

Table A1. Candidate items of benefits of sick child care services.

These services enabled me to work without sudden interruptions, preventing my income from decreasing

Because my child was taken care of by professionals, I was able to work free from anxiety

As I did not have to worry about leaving my workplace early, I could focus on my job free from anxiety

I could rely on sick child care staff by seeking professional advice

I was relieved that I was able to place my child in a care facility

I did not have to worry about causing trouble for my relatives or acquaintances

I was able to learn how to take care of sick children

My child could receive appropriate care provided by professionals

My child achieved health recovery early

They were useful to prevent my child's disease from deteriorating (there had been no recurrence)

At the care facility, my child was able to play as usual

My child was not forced to go to the usual nursery or preschool despite being in poor health

I was able to work without suddenly being absent from work or troubling my co-workers

We did not have to use medical services during the night-time or on out-of-service days

I could focus on my work and house chores with a sense of ease

I worried that my child might contract infectious diseases from other children

I was relieved that the care facility had rooms intended only for children with infectious diseases

It was hard for me to work with my sick child left in others' care*

${ }^{*}$ The selected score was inversely calculated.

Table A2. Candidate items of parents’ requests regarding sick child care.

I desire an increase in the number of care facilities

I also wish that these services were available in my child's usual nursery school

I desire an increased capacity to accept children

I hope that their service hours could be extended

I wish that nurseries were open on weekends and holidays

I desire an increase in the number of nursery staff members

I desire an increase in the number of nurses

I desire information regarding sick child care

I desire lower care fees

I desire more public subsidies according to the income

I desire a reduction in fees for nursery school and sick child care when using such care

I desire financial support from my workplace

I wish that care fees were fully subsidized 


\section{Submit or recommend next manuscript to SCIRP and we will provide best service for you:}

Accepting pre-submission inquiries through Email, Facebook, LinkedIn, Twitter, etc.

A wide selection of journals (inclusive of 9 subjects, more than 200 journals)

Providing 24-hour high-quality service

User-friendly online submission system

Fair and swift peer-review system

Efficient typesetting and proofreading procedure

Display of the result of downloads and visits, as well as the number of cited articles

Maximum dissemination of your research work

Submit your manuscript at: http://papersubmission.scirp.org/ 